\title{
Examination of the Biodiesel Production Performances of Natural and Modified Bentonite Heterogeneous Basic Catalysts
}

\section{Sema ASLAN ${ }^{1 *}$}

\begin{abstract}
Intension of this study is the production of an alternative energy source from rapeseed oil with renewable heterogeneous basic catalysts. Production of biodiesel from biomass has been studied over decades and the positive effects of the heterogeneous basic catalysts on this process are still worth to examine. In the presented study firstly, natural bentonite (BT) was activated by calcination to obtain calcinated bentonite (C-BT). Then Li impregnation experiments were completed, and Li impregnated bentionite (Li-BT) catalyst was prepared. Obtained catalysts were characterized and analysed with FTIR, TGA and SEM/EDS measurements. Measurements showed that Li-BT is a promising catalyst and due to Li impregnation, exchange ability of the surface of the BT increased. Subsequently, they were utilized to the biodiesel production from rapeseed oil process individually and total fatty acid methyl ester yields of the obtained biodiesel were examined by GC-MS measurements. As a result, the best conversion yield was obtained from Li-BT used experiments as $98.80 \%$ besides C-BT revealed with no yield. These studies can be enlarged by the consecutive catalytic experiments in detail. In conclusion, there is no need to use expensive catalysts and petroleum sourced hazardous chemicals to produce renewable energy catalysts.
\end{abstract}

Keywords: Heterogeneous basic catalyst, Biodiesel, Rapeseed oil, Bentonite, Renewable energy

${ }^{1}$ Sema ASLAN (Orcid ID: https://orcid.org/0000-0001-9796-7311), Muğla Sıtkı Koçman Üniversitesi, Fen Fakültesi, Kimya Bölümü, Muğla, Türkiye

*Sorumlu Yazar/Corresponding Author: Sema ASLAN, e-mail: semaaslan@mu.edu.tr

Geliş tarihi / Received: 09-10-2019

Kabul tarihi / Accepted: 05-01-2020 


\section{INTRODUCTION}

It is clear that pollution levels are reaching higher grades and cause deterioration of the health of the live organisms (Tursi, 2019). Especially petroleum sourced pollution increasing by the usage of fossil fuels for industrial or postindustrial studies. These effects lead the researchers to find out more and more renewable energy sources (Chen, 2017). Thus biomass usage is preferred instead of conventional energy sources (Sani et al., 2014). It should be noted that it is a completely renewable source because it releases biogenic originated $\mathrm{CO}_{2}$ to the atmosphere and plants use this $\mathrm{CO}_{2}$ for their growth and metabolic processes (Tkemaladze and Makhashvili, 2016, Sun et al., 2010). As biodiesel is a renewable and environmentally friendly fuel, it shows great potential as an alternative energy source (Guyon and Elisseeff, 2003; Rana et al., 2018). It is produced by many divergent methods (microwave-assisted (Moser, 2009; Kumar et al., 2011), sonication (Al-Ani et al., 2018), direct transesterification (Aslan et al., 2019), microbial (Akia et al., 2014) or sources, different kinds of raw materials can be used (refine, crude or frying oils) (Li et al., 2014), or there are different types of catalyst utilization, beyond acids or bases (Karahan et al., 2016; Donmez et al., 2018; Gungor et al., 2018; Kara et al., 2018), photocatalysts (Uğurlu et al., 2006; Karaoğlu et al., 2010; Karaoğlu and Uğurlu, 2010; Dinçer et al., 2016) ion exchange resins, lipases or supercritical fluids are used (Marchetti and Erazzu, 2008; Duan and Savage., 2011). Generally, biodiesel is produced by the transesterification reaction of triglycerides with short chain alcohols in the presence of a suitable catalyst (Izadpanahi et al., 2012).

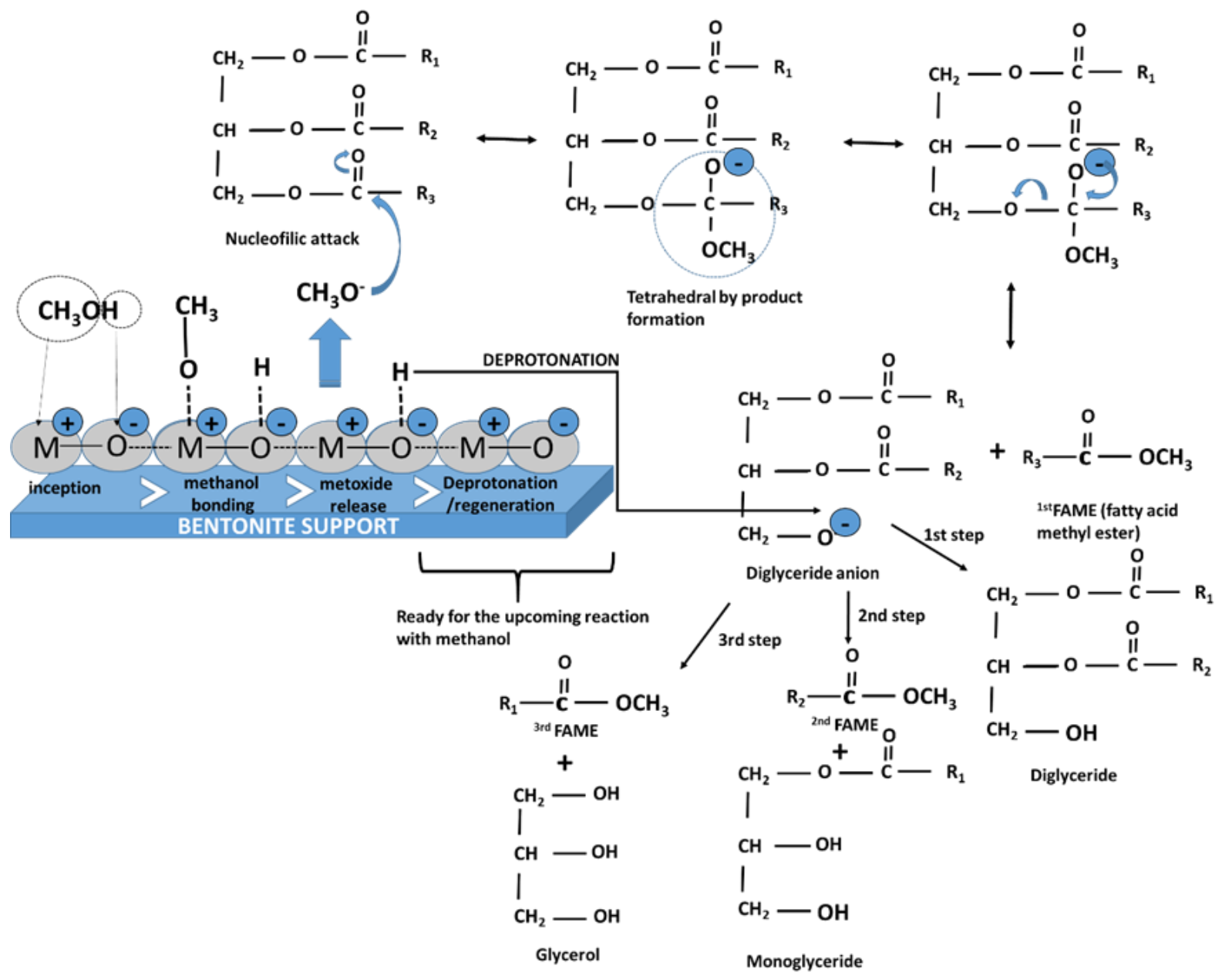

Scheme 1. Methoxide formation on the BT support and the reaction mechanism of biodiesel formation 
Catalyst transesterification reactions are mostly carried out by using alkaline, acidic or enzymatic catalysts (Duan and Savage, 2011). Recently, microporosis heterogeneous catalysts such as zirconium (Erkarslan et al., 2018), sulfated zirconium and titanium based zeolite have been used in the biodiesel production from different oil sources (Haupt and Haupt, 2004). The transesterification reaction takes place at a temperature of $250{ }^{\circ} \mathrm{C}$ in the catalyst-free environment but the same reaction can be successfully operated at lower temperatures by the usage of acidic (Suryaputra et al., 2013), alkaline or heterogeneous catalysts (Kennedy and Eberhart, 2001; Poore et al., 2012). Biodiesel production was achieved by a transesterification reaction in the reflux set up. The transesterification reaction is the conversion of triglycerides into fatty acid methyl esters (FAME) and glycerol (Scheme 1).

In recent years, efforts to develop heterogeneous catalysts (Karaoğlu et al., 2012; Dinçer at al., 2016) have been accelerated to use in biodiesel production. Post-process separation, lack of purification processes, eliminating the neutralization step of free fatty acids, no saponification of triglycerides, no catalytic residue in methyl ester and glyceride, and making production more economical are the main reasons for this development (Karaoglu and Ugurlu, 2011; Wang et al., 2019). At the same time, high product conversion can be achieved in heterogeneous catalysts and these eco-friendly catalysts are renewable catalysts (Li and Chung, 2008, Soetaredjo et al., 2011, Sen et al., 2016).

In this study, bentonite (BT) was activated by calcination (C-BT) and Li impregnated bentonite (Li-BT) was produced. Two different basic heterogeneous catalysts were utilized for the biodiesel production from rapeseed oil by transesterification method. For this purpose, the morphological and analytical characteristics of the catalysts and biodiesels were investigated with SEM/EDS, FTIR, TGA and GC-MS analysis. Li-BT revealed the best biodiesel conversion performance due to the presence of $\mathrm{Li}$ ions rather than being able to replace $\mathrm{H}^{+}$atoms in order to obtain methoxide from methanol in the first step of biodiesel production process.

\section{MATERIALS AND METHODS}

\section{Materials}

Methanol (99.80\% pure), n-hexane (99.00\% pure), natrium sulfate (99.00\% pure) and lithium acetate $(99.00 \%$ pure) were purchased from Merck. BT was supplied from a local plant. Rapeseed oil was obtained from a local market (Aypa Co.).

\section{Experimental Procedure \\ Preparation of the heterogeneous catalysts}

Firstly natural BT particles were minimized in a mortar and sieved into $350.00 \mu \mathrm{m}$. Then obtained particles were activated by calcination at $500.00{ }^{\circ} \mathrm{C}$ for 2.00 hours. This form of BT was used as C-BT and a suitable amount of this sample kept for the experiments.

Subsequently, in order to produce $\mathrm{Li}-\mathrm{BT}, 5.88 \mathrm{~g}$ of $\mathrm{CH}_{3} \mathrm{COOLi}_{(\mathrm{s})}$ was dissolved in $500.00 \mathrm{~mL}$ of deionized pure water in a suitable flask and $20.00 \mathrm{~g}$ of C-BT was added to this solution. The obtained mixture was maintained at $60.00{ }^{\circ} \mathrm{C}$ and stirred mechanically for $24.00 \mathrm{~h}$. The resulting slurry was transferred to drying owen at $110.00{ }^{\circ} \mathrm{C}$ for $24.00 \mathrm{~h}$. Finally calcination was operated at $500.00{ }^{\circ} \mathrm{C}$ for $5.00 \mathrm{~h}$. Then, these samples were transferred into a desiccator, cooled and stored in dark medium when not in use (Omar and Amin, 2011). 
The morphological and structural properties of the C-BT and Li-BT catalysts were investigated by TGA, FT-IR (Perkin Elmer), SEM (JEOL, JSM-7600F scanning electron microscope) and EDS analysis.

\section{Transesterification and biodiesel production process}

Biodiesel is the total FAME content of the mixture. Firstly, methanol (methanol/oil; 6/1) and a small quantity of heterogeneous catalyst $(6.00 \%)$ were transferred to the reflux condenser adapted three-neck flask. Heated and stirred at $60.00{ }^{\circ} \mathrm{C}$ for $1 \mathrm{~h}$ in order to obtain methoxide groups on the heterogeneous catalyst. Subsequently, rapeseed oil was added to the mixture and stirred for $3.00 \mathrm{~h}$ at the same conditions. Then the mixture was cooled down to room temperature. Obtained samples were centrifuged for $15.00 \mathrm{~min}$ at $5000.00 \mathrm{rpm}$ and the supernatant solution was washed and dried with natrium sulfate anhydrous. Finally, excess methanol was evaporated at $105.00{ }^{\circ} \mathrm{C}$. Total FAME content of the analyzed by GC-MS (Omar and Amin, 2011).

\section{RESULTS AND DISCUSSION}

\section{Chemical Characterizations of Catalysts}

\section{FTIR spectroscopy analysis}

The FTIR spectra of natural BT, C-BT, and Li-BT were analyzed in order to explain structural changes after the calcination and Li impregnation process (Figure 1). There has been a decrease at the peak of natural BT in the field of $\mathrm{OH}$ vibration after the calcination $\left(3625.63 \mathrm{~cm}^{-1}\right)$, so as the $\mathrm{OH}$ bending of zeolitic water $\left(1636.55 \mathrm{~cm}^{-1}\right)$ depending on the removal of humidity in the natural BT structure. It can be concluded that after calcination of BT, CO bending peak is suppressed but after Li impregnation, the interaction between $\mathrm{CO}$ group and $\mathrm{Li}$ ions increased the peak $\left(2157.71 \mathrm{~cm}^{-1}, 2159.99 \mathrm{~cm}^{-1}, 2160.57\right.$ $\mathrm{cm}^{-1}$, respectively). About the fingerprint area, the $1009.16 \mathrm{~cm}^{-1}$ peak of the natural BT corresponds to the C-C single bond or Si-O-Si vibrations and as it seems from the spectra this bond is suppressed after the calcination but increased again after the Li impregnation. Finally, the peak at the $793.81 \mathrm{~cm}^{-1}$ in the fingerprint area shows the same behavior (Cobas et al., 2014; Eren et al., 2009). These results mean that calcination was achieved successfully and $\mathrm{Li}$ interactions were observed especially with $\mathrm{C}-\mathrm{C}$ and $\mathrm{C}=\mathrm{O}$ bonds.

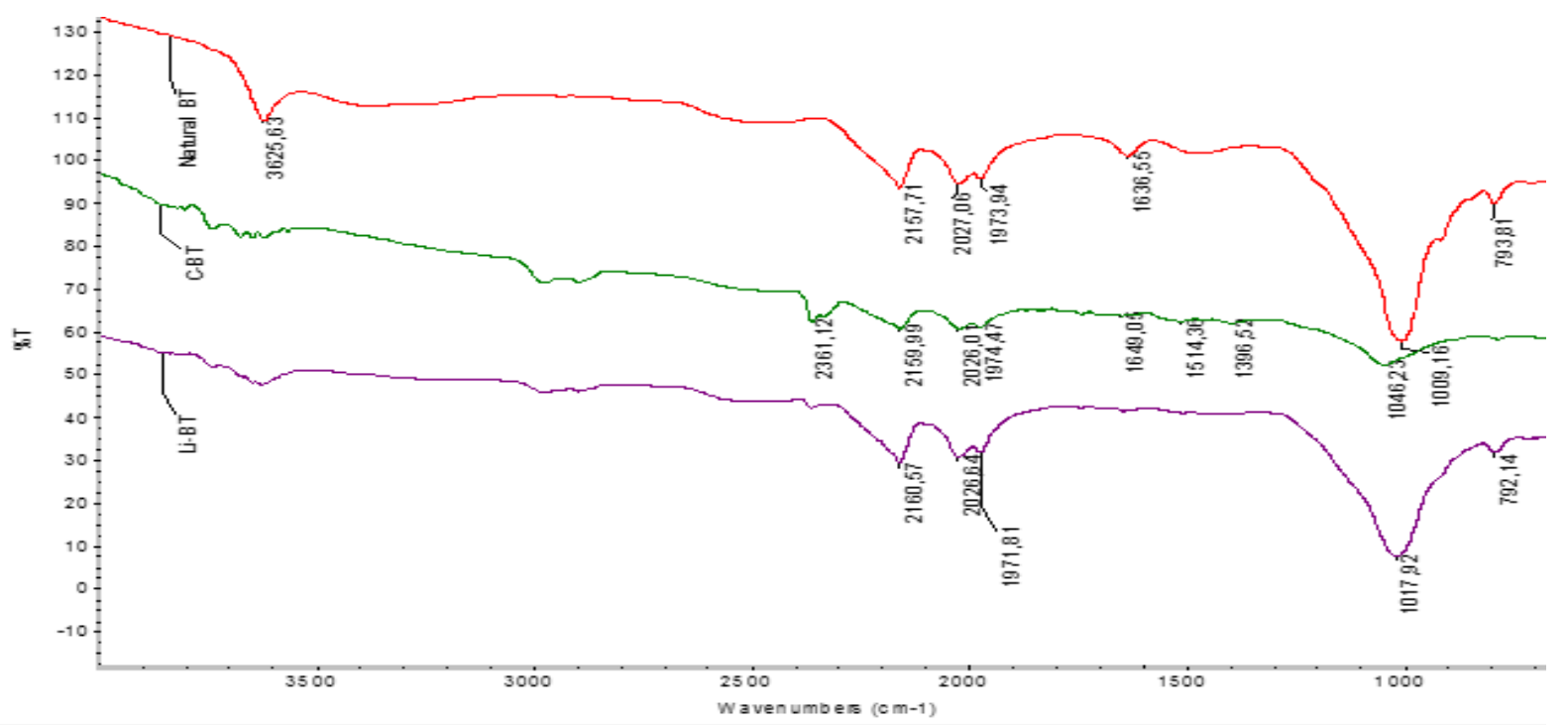

Figure.1. Comparison of the FTIR analysis of natural BT, C-BT, and Li-BT $\left(4000-400 \mathrm{~cm}^{-1}\right)$ 


\section{TGA analysis of catalyst}

Thermogravimetric analysis of natural, calcinated and Li impregnated BTs were performed to validate FTIR results. Weight loss percentages of natural BT is higher than C-BT (Figure 2a) and Li-BT (Figure 2b). As it has been mentioned above, there is a water presence in the natural BT structure. So, the weight loss at $100.00{ }^{\circ} \mathrm{C}$ is attributed to the water content of the $\mathrm{BT}$ and after the calcination, no weight loss is observed in this area for both C-BT and Li-BT samples. Additionally, between 600.00$700.00{ }^{\circ} \mathrm{C}$ maximum carbon dioxide release belongs to the natural BT, then C-BT and finally Li-BT. These results can be explained by the presence of Li interaction between $\mathrm{C}$ atoms.
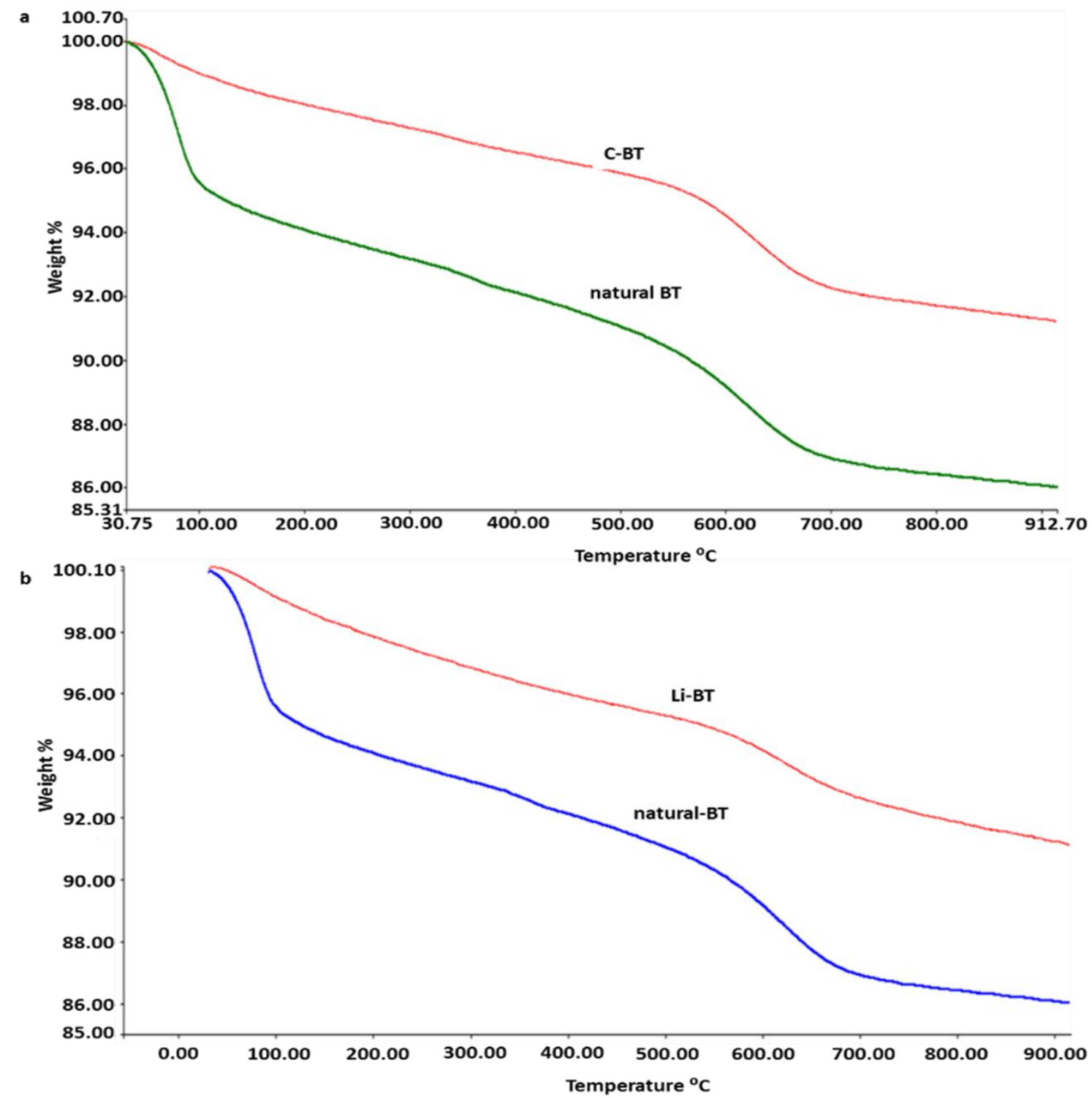

Figure 2. Comparison of the TGA analysis of a) natural BT and C-BT, b) natural BT and Li-BT $\left(21-900{ }^{\circ} \mathrm{C}\right)$

\section{SEM and EDS analysis of catalysts}

The morphological properties of the catalysts were monitored with SEM and EDS analysis. Here the SEM images and EDS values of C-BT and Li-BT are presented and compared with each other. Since Li element shows the EDS peak around $0.02 \mathrm{keV}$ it was expected to be overlapped by $\mathrm{C}$ and $\mathrm{K}$ peaks in the spectrum additionally if the irradiation beam of the electrode isn't high enough to indicate the Li ion it can't be seen or indicated as another ion here such as K. As it is reported (Hovington et al., 2017) 
lithium is highly mobile under the electron beam and therefore any quantitative measurements should be treated with caution. According to the EDS values, the change in the elemental composition of C-BT is attributed to the successful impregnation with $\mathrm{Li}$ on the surface of BT. Besides SEM image of the LiBT shows morphological differences compared to the C-BT surface it can be concluded that $\mathrm{Li}$ impregnation was achieved successfully.
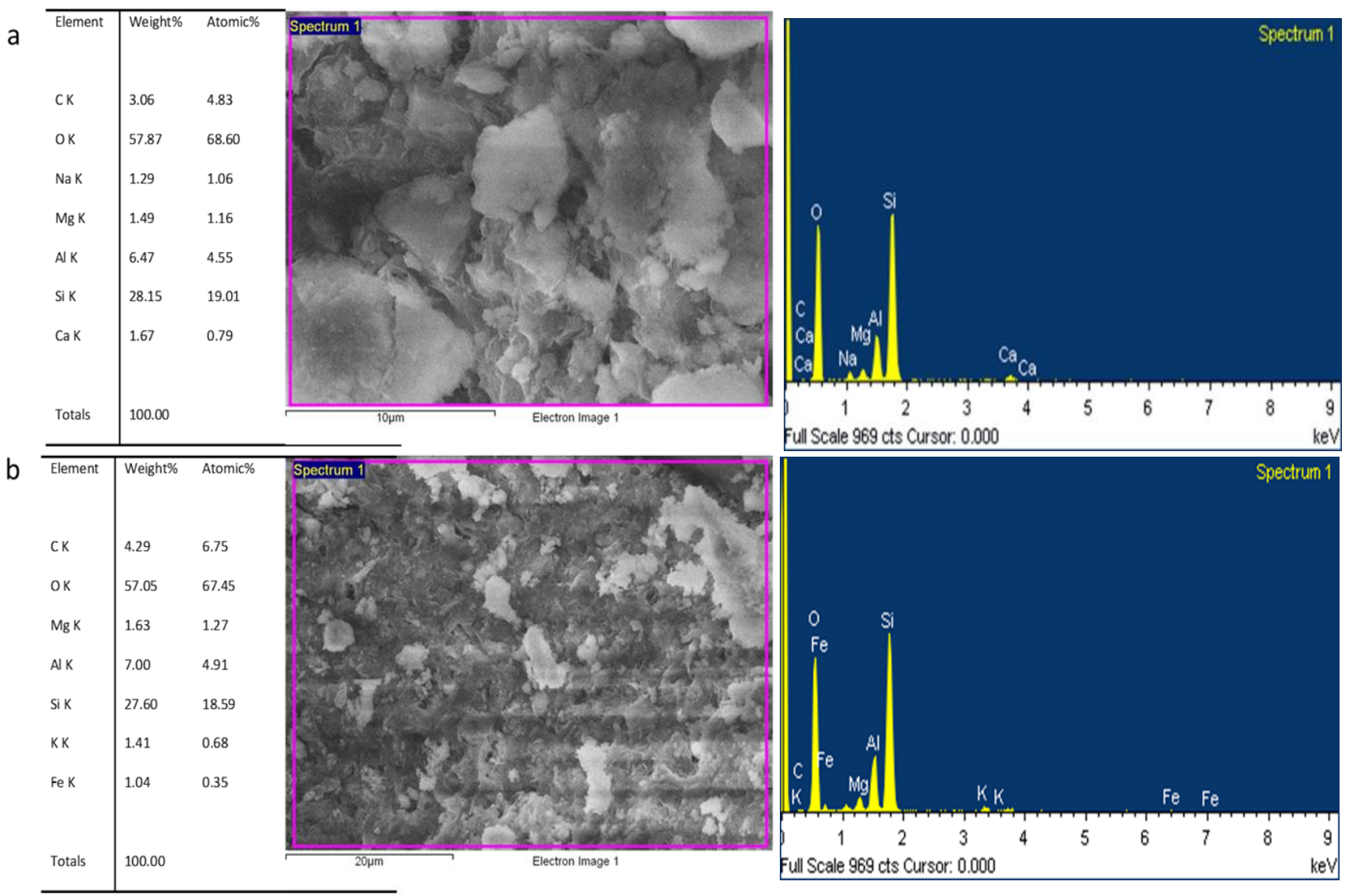

Figure 3. Comparison of the EDS analysis results and SEM imaginations of a) C-BT, b) Li-BT.

\section{Evaluation of the biodiesel production performance of Li-BT.}

The fuel properties of biodiesel are indicated according to the FAME composition, along with the presence of other contaminants as water or alcohol and minor components such as sulphur, phosphines or iodide. This hint leads the researchers to explore suitable feedstock because each feedstock has its unique chemical composition. Another crucial point is conversion achievement after the process completed. At this point, GC-MS analysis of produced biodiesel is necessary (Dias et al., 2008). Total FAME content of biodiesel fuel indicates the quality of the components of whole process; beginning from feedstock choice goes on with true catalyst choice and ends with convenient purification. Here the results of the GC-MS analysis (Figure 4) are given in detail in Table 1 with peak area percentages of corresponding FAME types. 


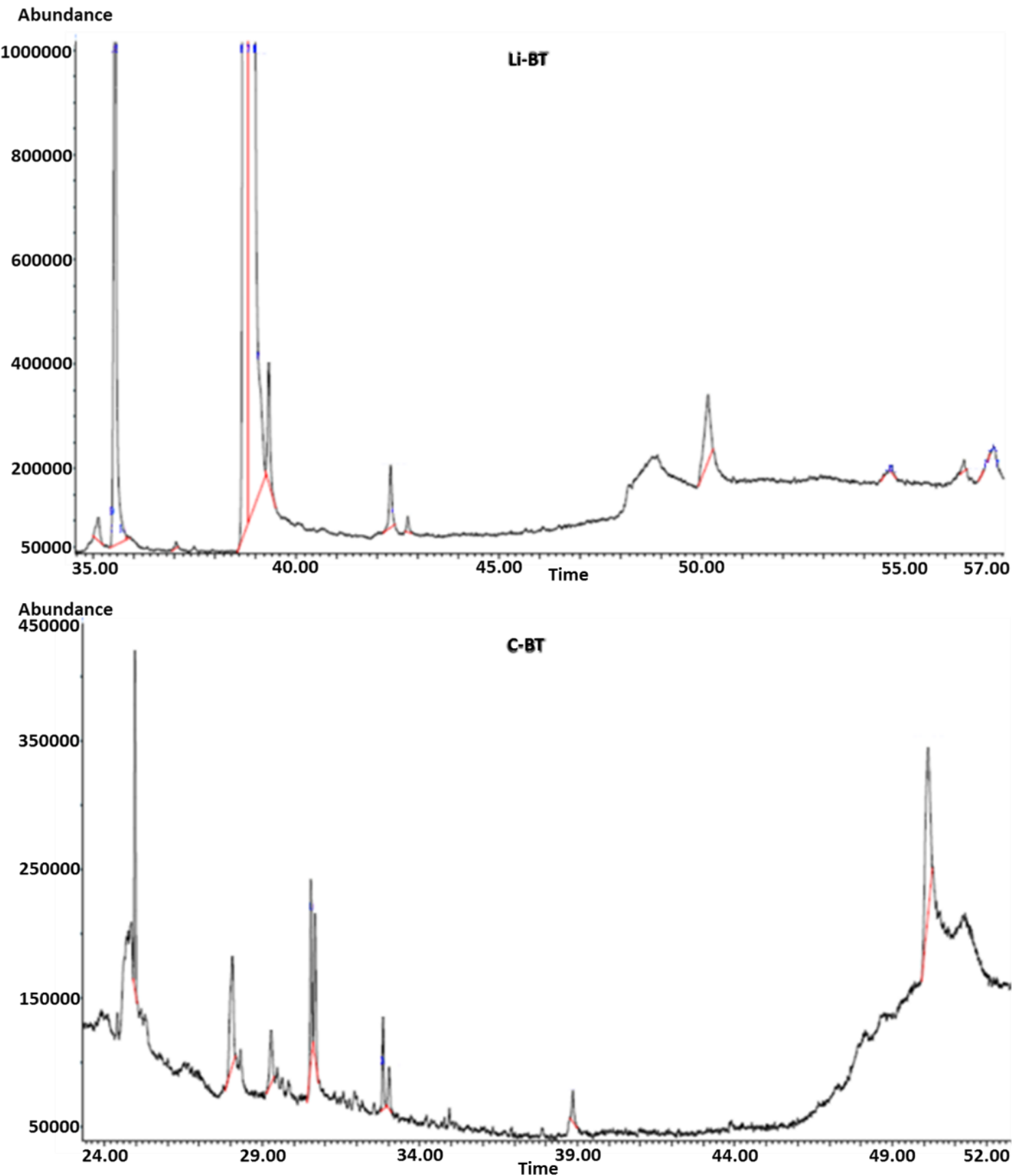

Figure 4. GC-MS spectra of the biodiesel products of Li-BT and C-BT catalysts.

Table 1. FAME composition of the final biodiesel product of Li-BT catalysed process

\section{FAME type}

Methyl palmitate hexadecanoic acid

6-Methoxybenzofuroxan

Methyl linoleate

Oleic acid methyl ester

Methyl stearate

cis-11-Eicosenoic acid methyl ester

Arsenous acid, tris(trimethylsilylester)
Unit quantity of the product (peak area \%)
3.86
0.16
30.84
63.31
0.56
0.06
0.01 
Another important biodiesel quality determination factor is the carbon to hydrogen ratio. According to the heat of combustion, values FAME have similar chain length can show different energy outputs. If they have lower carbon to hydrogen ratios, mainly containing more hydrogen than carbon, they exhibit greater energy values. For instance, stearic acid methyl esters (largest hydrogen content) show greater energy yields than oleic, linoleic, and linolenic (smallest hydrogen content) acids [12]. Therefore, lower energy potential is obtained from regularly higher levels of unsaturation with otherwise similar chain length (DeOliviera et al., 2006). Obtained results indicate the expected energy value of the presented biodiesel is low but the conversion percentage is very satisfactory. Because the oleic and linoleic acid methyl ester amounts are major elements in the final fuel (30.84 and $63.31 \%$ respectively) $\mathrm{C}$ to $\mathrm{H}$ ratio of the fuel is expected to be low.

\section{CONCLUSION}

The choice of the feedstock is a very crucial point to determine final fuel FAME quality and so as the alcohol type which is used for esterification reaction. Besides, homogeneous catalyst usage results in saponification that is lethal for the transesterification process. The most important point to be emphasized here is the use of BT as a highly economical and effective heterogeneous catalyst.

Biodiesel conversion is very satisfactory but the quality of final fuel ingredients can be lifted by the choice of stearic acid rich feedstock choice. Also, the reflux method is very conventional but this process is ready to try with microwave assisted system with shorter reaction times.

\section{ACKNOWLEDGEMENTS}

The author is grateful to Prof. Dr. M. Hamdi KARAOGLU (Muğla Sitkı Koçman University, Department of Chemistry) for his very valuable scientific mentorship.

\section{REFERENCES}

Akia M, Yazdani F, Motaee E, Han D, Arandiyan H, 2014. A review on conversion of biomass to biofuel by nanocatalysts. Biofuel Res J 1(1): 16-25.

Al-Ani A, Darton RJ, Sneddon S, Zholobenko V, 2018. Nanostructured Zeolites: The Introduction of Intracrystalline Mesoporosity in Basic Faujasite-type Catalysts. ACS Appl. Nano Mater. 1: 310-318.

Aslan S, Aka, N, Karaoğlu MH, 2019. NaOH impregnated sepiolite based heterogeneous catalyst and its utilization for the production of biodiesel from canola oil. Energy Sources, Part A: Recovery, Utilization, And Environmental Effects 41:290-297.

Chen J, Li C, Ristovski Z, Milic A, Gu Y, Islam MS, Wang, S, Hao J, Zhang H, He C, Guo H, Fu H, Miljevic B, Morawsk L, Thai P, 2017. A review of biomass burning: Emissions and impacts on air quality, health and climate in China. Sci Total Environ 579:1000-1034.

Cobas M, Ferreira L, Sanroman MA, Pazos M, 2014. Assessment of sepiolite as a low-cost adsorbent for phenanthrene and pyrene removal: Kinetic and equilibrium studies. Ecological Engineering 40: 28794.

DeOliveira E, Quirino RL, Suarez PAZ, Prado AGS, 2006. Heats of combustion of biofuels obtained by pyrolysis and by transesterification and of biofuel/diesel blends. Thermochim. Acta 2006, 450: 87-90.

Dias JM, Alvim-Ferraz MCM, Almeida MF, 2008. Comparison of the performance of different homogenous alkali catalysts during transesterification of waste and virgin oils and evaluation of biodiesel quality. Fuel 87: 3572-3578.

Dinçer F, Karaoğlu MH, Uğurlu M, Vaizoğullar A, 2016. Ozonation of Reactive Orange 122 Using La3+Doped WO3/TiO2/Sep Photocatalyst. Ozone: Science and Engineering 38 (4):291-301.

Dinçer F, Karaoğlu MH, Uğurlu M, Vaizoğullar A, 2016. Ozonation of Reactive Orange 122 Using La3+Doped WO3/TiO2/Sep Photocatalyst. Ozone: Science and Engineering 38 (4): 291-301. 
Donmez A, Coban MB, Kara H, 2018. Cyan-Blue Luminescence and Antiferromagnetic Coupling of CNBridged Tetranuclear Complex Based on Manganese(III) Schiff Base and Hexacyanoferrate(III). Journal of Cluster Science 29 (6):951-958.

Duan P, Savage PE, 2011. Hydrothermal Liquefaction of a Microalga with Heterogeneous Catalysts Ind. Eng. Chem. Res. 50(1): 52-61.

Eren E, Cubuk O, Ciftci H, Eren B, Caglar B, 2010. Adsorption of basic dye from aqueous solutions by modified sepiolite: Equilibrium, kinetics and thermodynamics study. Desalination 252:88-96.

Erkarslan U, Donmez A, Kara H, Aygun M, Coban MB, 2018. Synthesis, Structure and Photoluminescence Performance of a New Er3+-Cluster-Based 2D Coordination Polymer. Journal of Cluster Science 29 (6): 1177-1183.

Gungor E, Coban MB, Kara H, 2018. Photoluminescence and Magnetism Study of Blue Light Emitting the Oxygen-Bridged Open-Cubane Cobalt(II) Cluster. Journal of Cluster Science 29 (6): 967-974.

Guyon I, Elisseeff A. 2003. An introduction to variable and feature selection. J Mach Learn Res 3: 11571182.

Haupt RL, Haupt SE, 2004. Practical Genetic Algorithms. 2nd ed. Wiley. New York. USA.

Hovington P, Timoshevskii V, Bessette S, Burgess S, Statham P, Demers H, Gauvin R, Zaghib K, 2017. On the Detection Limits of Li K X-rays Using Windowless Energy Dispersive Spectrometer (EDS). Proceedings of Microscopy \& Microanalysis 23: 2024-2025

Izadpanahi S, Ozcınar C, Anbarjafari G, Demirel H, 2012. Resolution enhancement of video sequences by using discrete wavelet transform and illumination compensation. Turk J Elec Eng \& Comp Sci 20: 1268-1276.

Kara DA, Donmez A, Kara H, Burak Coban M, 2018. Structural and spectroscopic characterization of a new luminescent NiII complex: Bis\{2,4-dichloro-6-[(2-hydroxypropyl)iminomethyl]phenolato-

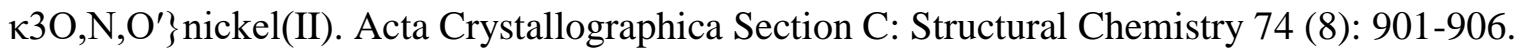

Karahan A, Kurtaran R, Yahsi Y, Gungor E, Kara H, 2016. A dinuclear oxygen-bridged Schiff base iron(III) complex derived from N,N'-bis(4-methoxy-2-hydroxybenzylidene)-2,2-dimethylpropane-1,3diamine. Journal of Structural Chemistry 57 (4): 731-736.

Karaoğlu MH, Doğan M, Alkan M, 2010. Removal of reactive blue 221 by kaolinite from aqueous solutions. Industrial and Engineering Chemistry Research 49 (4): 1534-1540.

Karaoğlu MH, Doğan M, Alkan M, Uğurlu M, 2012. Photooxidative degradation of cationic dyes using $\mathrm{UV} / \mathrm{H} 2 \mathrm{O} 2$ and UV/H2O2/TiO2 process. Fresenius Environmental Bulletin 21 (7): 1758-1763.

Karaoğlu MH, Uğurlu M, 2010. Kinetic and equilibrium studies of methylene blue biosorption by vineyard pruning waste. Fresenius Environmental Bulletin 19 (12): 3199-3208.

Karaoglu MH, Ugurlu M, 2011. Adsorption and recovery of methylene blue from aqueous solution by $\mathrm{NaOH}$-treated of prina. Asian Journal of Chemistry 23 (6): 2577-2583.

Kennedy J, Eberhart R, 2001. Swarm Intelligence. Academic Press. San Diego, CA. USA.

Kumar R, Kumar GR, Chandrashekar N, 2011. Microwave assisted alkali-catalyzed transesterification of Pongamia pinnata seed oil for biodiesel production. Bioresour Technol 102: 6617-6620.

Li M, Zheng Y, Chen Y, Zhu X, 2014. Biodiesel production from waste cooking oil using a heterogeneous catalyst from pyrolyzed rice husk. Bioresour Technol 154:345-348.

Li RTH, Chung SH, 2008. Digital boundary controller for single-phase grid-connected CSI. In: IEEE 2008 Power Electronics Specialists Conference; 15-19 June 2008; Rhodes, Greece. New York, NY, USA: IEEE. pp. 4562-4568.

Marchetti JM, Errazu AF, 2008. Technoeconomic study of supercritical biodiesel production plant. Energy Convers. Manage 49: 2160-2164.

Moser BR, 2009. Biodiesel production, properties, and feedstocks. In Vitro Cell.Dev.Biol.-Plant 45: 229266. 
Omar WNNW, Amin NAS, 2011. Biodiesel production from waste cooking oil over alkaline modified zirconia catalyst. Fuel Proceeding Technology 92:2397-405.

Poore JH, Lin L, Eschbach R, Bauer T, 2012. Automated statistical testing for embedded systems. In: Zander J, Schieferdecker I, Mosterman PJ, editors. Model-Based Testing for Embedded Systems. pp. 111-146. CRC Press. Boca Raton, FL, USA.

Rana R, Nanda S, Meda V, Dalai AK, Kozinski JA, 2018. A review of lignin chemistry and its biorefining conversion technologies. J. Biochem. Eng. Bioprocess. Technol. 1(2).

Sani YM, Daud WMAW, Abdul Aziz AR, 2014. Activity of solid acid catalysts for biodiesel production: a critical review. Appl Catal A Gen 470: 140-161.

Sen I, Kara H, Azizoglu A, 2016. Substituent effects on hydrogen bonding of aromatic amide-carboxylate. Spectrochimica Acta - Part A: Molecular and Biomolecular Spectroscopy 167 (5): 50-58.

Soetaredjo FE, Ayucitra A, Ismadji S, Maukar AL, 2011. KOH/bentonite catalysts for transesterification of palm oil to biodiesel. Applied Clay Science 53:341-46.

Sun H, Ding Y, Duan J, Zhang Q, Wang Z, Lou H, Zheng X., 2010. Transesterification of sunflower oil to biodiesel on $\mathrm{ZrO} 2$ supported La2O3 catalyst. Bioresource Technology 101: 953-958.

Suryaputra W, Winata I, Indraswati N, Ismadji S, 2013. Waste capiz (Amusium cristatum) shell as a new heterogeneous catalyst for biodiesel production. Renew Energy 50: 795-799.

Tkemaladze GS, Makhashvili KA, 2016. Climate changes and photosynthesis. Ann Agrar Sci 14(2):119126.

Tursi A, 2019. A review on biomass: importance, chemistry, classification, and conversion. Biofuel Research Journal 22: 962-979.

Uğurlu M, Karaoğlu MH, Kula I. 2006. Experimental investigation of chemical oxygen demand, lignin and phenol removal from paper mill effluents using three-phase three-dimensional electrode reactor. Polish Journal of Environmental Studies 15 (4): 647-654.

Wang Z-C, Duan P-G, Liu X-J, Wang F, Xu Y-P, 2019. Hydrotreating the Low-Boiling-Point Fraction of Biocrude in Hydrogen Donor Solvents for Production of Trace-Sulfur Liquid Fuel. Industrial \& Engineering Chemistry Research 58 (24): 10210-10223. 